\title{
Analysis of STATCOM, SVC and UPFC FACTS Devices for Transient Stability Improvement in Power System
}

\author{
Pratheeksha R. ${ }^{1}$, K. M. Kavitha ${ }^{2}$ \\ ${ }^{1}$ Student, Electrical and Electronics Engineering Dept, AIT College, Chikkamagaluru-577102 Karnataka, India \\ ${ }^{2}$ Adjunct Faculty, Electrical and Electronics Dept., AIT College, Chikkamagaluru-577102 Karnataka, India
}

\begin{abstract}
The development of the modern power system has led to an increasing complexity in the study of power systems, and also presents new challenges to power system stability, and in particular, to the aspects of transient stability and small-signal stability. Transient stability control plays a significant role in ensuring the stable operation of power systems in the event of large disturbances and faults, and is thus a significant area of research. This paper investigates comparison of SVC, STATCOM and UPFC performance for the transient stability improvement of the power system. The improvement of transient stability of the power system, using SVC (Static VAR Compensator), STATCOM (Static Synchronous Compensator) and UPFC (Unified Power Flow Controller) which is an effective FACTS (Flexible AC Transmission System) device capable of controlling the active and reactive power flows in a transmission line by controlling appropriately parameters. Simulations are carried out in Matlab/Simulink environment. The performance of SVC, STATCOM\& UPFC is compared from each other. So for the improvement of transient stability STATCOM is better than SVC. The simulation results demonstrate the effectiveness and robustness of the proposed STATCOM, UPFC\& SVC on transient stability improvement of the system.
\end{abstract}

Keywords: FACTS, SVC, STATCOM, UPFC, Matlab/Simulink, Transient stability

\section{Introduction}

Modern power system is a complex network comprising of numerous generators, transmission lines, variety of loads and transformers. As a consequence of increasing power demand, some transmission lines are more loaded than was planned when they were built. With the increased loading of long transmission lines, the problem of transient stability after a major fault can become a transmission limiting factor [1]. Now power engineers are much more concerned about transient stability problem due to blackout in northeast United States, Scandinavia, England and Italy. Transient stability refers to the capability of a system to maintain synchronous operation in the event of large disturbances such as multi-phase short-circuit faults or switching of lines [2]. The resulting system response involves large excursions of generator rotor angles and is influenced by the nonlinear power angle relationship. Stability depends upon both the initial operating conditions of the system and the severity of the disturbance. Recent development of power electronics introduces the use of flexible ac transmission system (FACTS) controllers in power systems. FACTS controllers are capable of controlling the network condition in a very fast manner and this feature of FACTS can be exploited to improve the voltage stability, and steady state and transient stabilities of a complex power system [3-4]. This allows increased utilization of existing network closer to its thermal loading capacity, and thus avoiding the need to construct new transmission lines. Static VAR Compensator (SVC) is a first generation FACTS device that can control voltage at the required bus thereby improving the voltage profile of the system. The primary task of an SVC is to maintain the voltage at a particular bus by means of reactive power compensation (obtained by varying the firing angle of the thyristors) [5]. SVCs have been used for high performance steady state and transient voltage control compared with classical shunt compensation. SVCs are also used to dampen power swings, improve transient stability, and reduce system losses by optimized reactive power control [6-7].STATCOM, a shunt compensation device, from the family of flexible alternating current transmission systems (FACTS). The STATCOM is a solid-state voltage source converter which is tied to a transmission line. A STATCOM injects an almost sinusoidal current, of variable magnitude, at the point of connection. This injected current is almost in quadrature with the line voltage, thereby emulating an inductive or a capacitive reactance at the point of connection with the transmission line.

The benefits of utilizing FACTS devices in electrical transmission systems can be summarized as follows:

1. Better utilization of existing transmission system assets

2. Increased transmission system reliability and availability

3. Increased dynamic and transient grid stability and reduction of loop flows

4. Increased quality of supply for sensitive industries Environmental benefits.

\section{Static VAR Compensator (SVC)}

Static VAR systems are applied by utilities in transmission applications for several purposes. The primary purpose is usually for rapid control of voltage at weak points in a network. Installations may be at the midpoint of transmission interconnections or at the line ends. Static VAR Compensators are shunting connected static generators / absorbers whose outputs are varied so as to control voltage of the electric power systems. In its simple form, SVC is connected as Fixed Capacitor Thyristor 


\section{International Journal of Science and Research (IJSR) \\ ISSN (Online): 2319-7064}

Index Copernicus Value (2013): 6.14 | Impact Factor (2015): 6.391

Controlled Reactor (FC-TCR) configuration as shown in Figure 1.

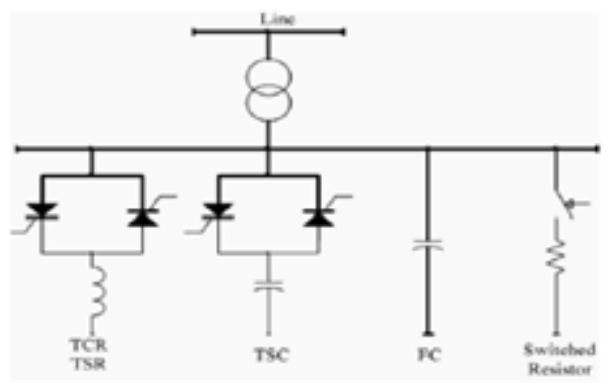

Figure 1: Static VAR Compensator (SVC)

The SVC is connected to a coupling transformer that is connected directly to the ac bus whose voltage is to be regulated. The effective reactance of the FC-TCR is varied by firing angle control of the anti-parallel thyristors. The firing angle can be controlled through a PI (Proportional + Integral) controller in such a way that the voltage of the bus, where the SVC is connected, is maintained at the reference value.

\section{Static Synchronous Compensator (STATCOM)}

The STATCOM is based on a solid state synchronous voltage source which generates a balanced set of three sinusoidal voltages at the fundamental frequency with rapidly controllable amplitude and phase angle. The configuration of a line voltage, thereby emulating an inductive or a capacitive reactance at the point of connection with the transmission line. STATCOM is shown in Figure 2.

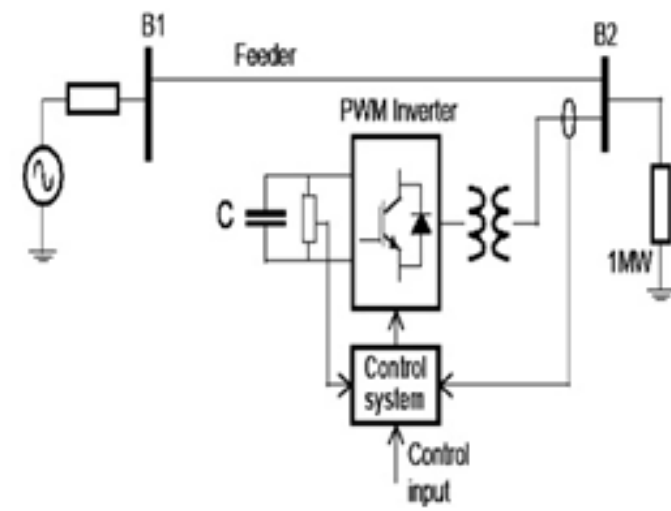

Figure 2: Static Synchronous Compensator (STATCOM)

\section{Unified Power Flow Controller (UPFC)}

Unified power flow control is a device nothing but a combination of series \& shunt facts device \& it obviously do the same work what is done by the series \& shunt fact device alone. It is the most powerful facts device [7] UPFC is mainly a combination of SSSC \& STATCOM. Used to improve the transient stability of the power system [8].The schematic figure of unified power flow controller is given below.

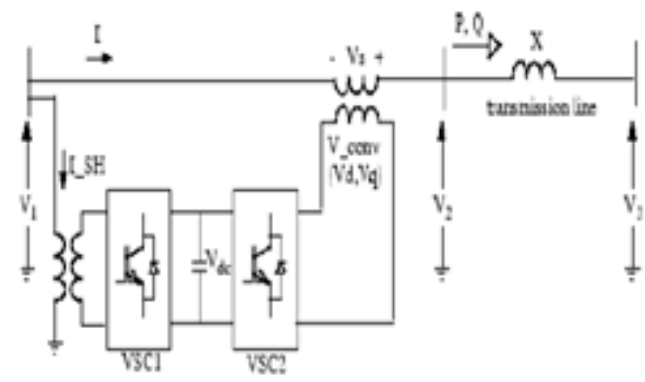

Figure 3: Unified Power Flow Controller (UPFC)

\section{Simulation Model}

A 3-bus system has been employed in Matlab/Simulink program to study the test system in detail. A single line diagram of the sample power transmission system shown in Figure 5.1.1 It has three RL load units (100MW, 2MW and $300 \mathrm{MW}$ ) and two $500-\mathrm{kV}$ equivalent source (respectively 3000 MVA and 2500 MVA) with a $600 \mathrm{~km}$ long transmission line. When the FACTS device is not in operation, the "natural" power flow on the transmission line is $855.5 \mathrm{MW}$ from bus B1 to B3.

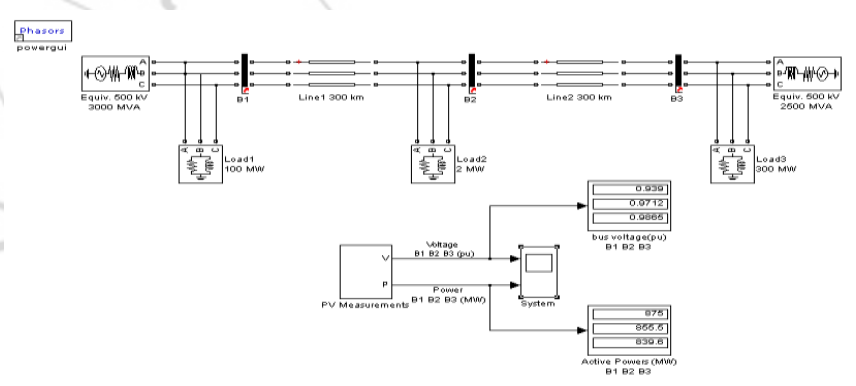

The voltage and power at the various buses is as tabulated below:

\begin{tabular}{|c|c|c|c|}
\hline Parameter & Bus B1 & Bus B2 & Bus B3 \\
\hline Voltage in kV & 469.5 & 485.6 & 493.25 \\
\hline $\begin{array}{c}\text { Active power in } \\
\text { MW }\end{array}$ & 875 & 855.5 & 839.6 \\
\hline
\end{tabular}

A. Three Phase Fault in the Test System with STATCOM

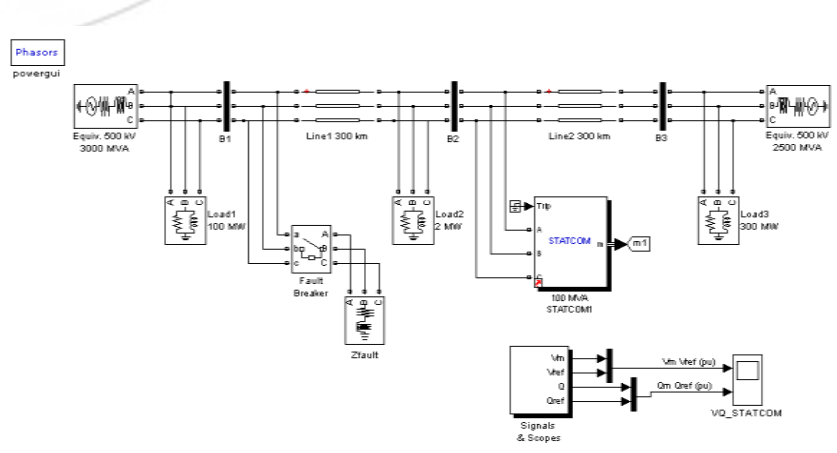




\section{International Journal of Science and Research (IJSR) \\ ISSN (Online): 2319-7064}

Index Copernicus Value (2013): 6.14 | Impact Factor (2015): 6.391

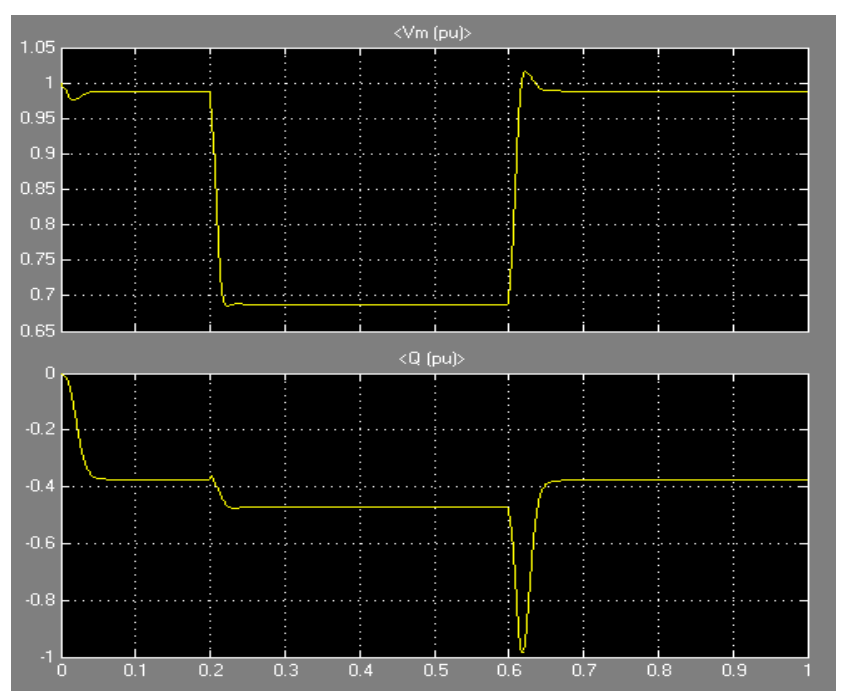

Figure 4: Waveforms of Voltage and Reactive power for STATCOM

B. Three Phase Fault in the Test System with SVC
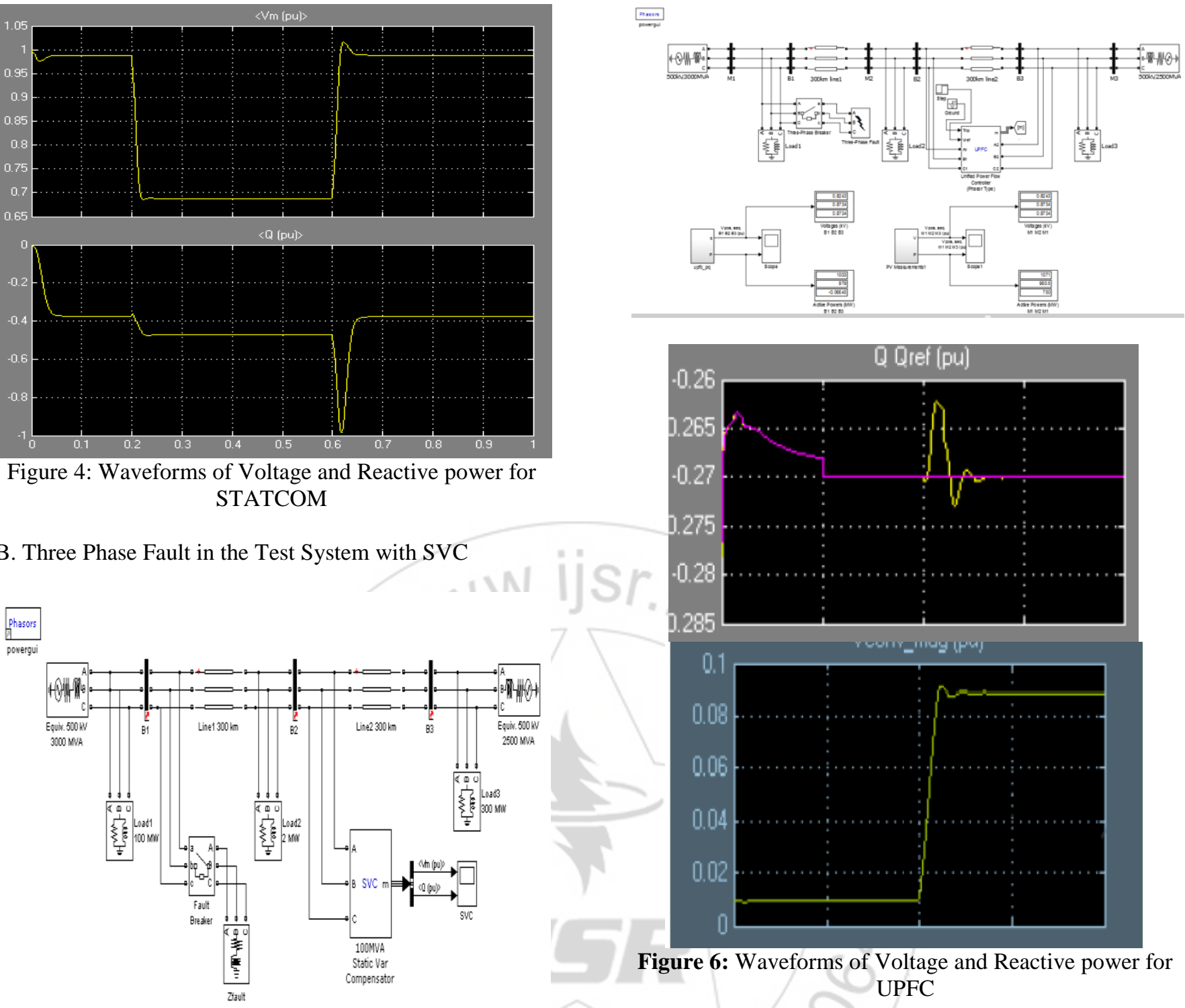

Figure 6: Waveforms of Voltage and Reactive power for UPFC

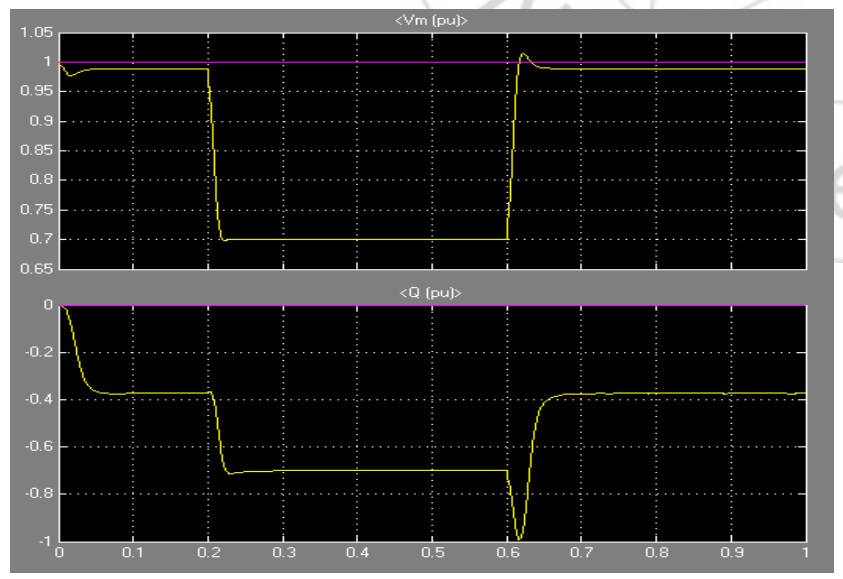

Figure 5: Waveforms of Voltage and Reactive power for SVC

C. Three Phase Fault in the Test System with UPFC

\section{Comparison of Statcom, SVC \& UPFC under Fault Condition}

We will now compare our STATCOM model with a SVC model having the same rating (+/- $100 \mathrm{MVA})$. If you double-click on the "SVC Power System" (the magenta block), you will see a SVC connected to a power grid similar to the power grid on which our STATCOM is connected. A remote fault will be simulated on both systems using a fault breaker in series with a fault impedance. Before running the simulation, you will first disable the "Step Vref" block by multiplying the time vector by 100 . Check alsothat the fault breaker inside the "SVC Power System" has the same parameters. Finally, set the STATCOM droop back to its original value (0.03 pu). Run the simulation and look at results. Difference between the SVC and the STATCOM can be observed. The reactive power generated by the SVC is $-0.7782 \mathrm{pu}$ and the reactive power generated by the STATCOM is $-0.8866 \mathrm{pu}$. We can then see that the maximum capacitive power generated by a SVC is proportional to the square of the system voltage while the maximum capacitive power generated by a STATCOM decreases linearly with voltage decrease (constant current). This ability to provide more 


\section{International Journal of Science and Research (IJSR) \\ ISSN (Online): 2319-7064}

Index Copernicus Value (2013): 6.14 | Impact Factor (2015): 6.391

capacitive power during a fault is one important advantage of the STATCOM over the SVC. In addition, the STATCOM will normally exhibit a faster response.

Initially the Bypass breaker is closed and the resulting natural power flow at bus B3 is $839 \mathrm{MW}$ and -27 Mvar. The Pref block is programmed with an initial active power of 8.39 pu corresponding to the natural power flow. Then, at $\mathrm{t}=10 \mathrm{~s}$, Pref is increased by $1 \mathrm{pu}(100 \mathrm{MW})$, from 8.39 pu to $9.39 \mathrm{pu}$, while Qref is kept constant at $-0.27 \mathrm{pu}$. The real and reactive powers increase with the increase in angle of injection. Simulation results show the effectiveness of UPFC to control the real and reactive powers. It is found that there is an improvement in the real and reactive powers through the transmission line when UPFC is introduced.

\section{Conclusion}

Among FACTS controllers, the shunt controller STATCOM have shown feasibility in terms of cost effectiveness in a wide range of problem-solving abilities from transmission to distribution levels. A comparison between the STATCOM and the SVC is made and based on several aspects it is concluded that a STATCOM is more preferred when compared to SVC and UPFC. Instead of directly deriving reactive power from the energy storage components, the STATCOM basically circulates power with the connected network .Even though UPFC has got both real and reactive power exchange and it is of high cost.

\section{References}

[1] R. Mihalic, P. Zunko and D. Povh, 1996, "Improvement of Transient Stability using Unified Power Flow Controller," IEEE Transactions on Power Delivery, 11(1),pp. 485-491.

[2] K.R. Padiyar, 2002, "Power System Dynamic Stability and Control," Second Edition, BS Publications, Hyderabad.

[3] Igor Papic, Peter Zunko, 2002, "Mathematical Model and Steady State Operational Characteristics of a Unified Power Flow Controller," Electro-technical Review, Slovenija, 69(5), pp. 285-290.

[4] S. Panda, Ramnarayan N. Patel, 2006, "Improving Power System Transient Stability with an off-centre Location of Shunt FACTS Devices," Journal of Electrical Engineering, 57(6), pp. 365-368

[5] N.G. Hingorani, L. Gyugyi, 1999, "Understanding FACTS: Concepts and Technology of Flexible AC Transmission Systems," IEEE Press, New York.

[6] N. Mithulananthan, C.A. Canizares, J. Reeve, Graham J. Rogers, 2003, "Comparison of PSS, SVC and STATCOM Controllers for Damping Power System Oscillations," IEEE Transactions on Power Systems, 18(2), pp. 786-792

[7] E.Z. Zhou, 1993, "Application of Static Var Compensators to Increase Power System damping," IEEE Transactions on Power Systems, 8(2), pp. 655661.

[8] H. SAADAT, H.: Power System Analysis, Tata McGraw-Hill, 2002
[9] N.G. Hingorani and L. Gyugyi, Understanding FACTS: Concepts and Technology of Flexible AC Transmission Systems. New York: IEEE Press, 2000.

[10] N.G. Hingorani, "FACTS-Flexible AC Transmission System", Proceedings of 5th International Conference on AC and DC Power Transmission-IEEE Conference Publication 345, 1991, pp. 1-7.

[11] N.G. Hingorani, "Flexible AC Transmission", IEEE Spectrum, April 1993, pp. 40-45.

[12]N.G. Hingorani, "High Power Electronics and Flexible AC Transmission System", IEEE Power Engineering Review, July 1988

[13] Habibur, Dr. Fayzur, Harun, 'Online voltage level improvement by using SVC \& PSS' "International Journal of system \& simulation". Vol. 06,No.02(Dec,2012) Issue(Received for publication)

[14] "MATLAB Math Library User's Guide", by the Math Works. Inc

[15] AmitGarg, "Modeling and Simulation of Static VAR Compensator for Improvement of Voltage Stability in Power System" ISSN: 2249-071X, Vol.2, Issue-2

[16] Ali M. Yousef "Transient stability Enhancement of multi machine using Global deviation PSS " Journal of Engineering sciences, Faculty of Engineering, Assiut University, Vol. 32, No.2 April 2004 pp. 665677.

[17]B.H. Li, Q.H. Wu, D.R. Turner, P.Y. Wang,X.X. Zhou, 2000, "Modeling of TCSC Dynamics for Control and Analysis of Power System Stability," Electrical Power \& Energy Systems, 22(1), pp. 43-49.

[18] A.D. Del Rosso, C.A. Canizares, V.M. Dona, 2003, "A Study of TCSC Controller Design for Power System Stability Improvement," IEEE Transactions on Power Systems, 18(4), pp. 1487-1496.

[19]L. Gyugyi, 1994, "Dynamic Compensation of AC Transmission Line by Solid State Synchronous Voltage Sources," IEEE Transactions on Power Delivery,9(22), pp. 904-911.

[20]M. Noroozian, L. Angquist, M. Ghandhari, G.Andersson, 1997, "Use of UPFC for Optimal Power Flow Control," IEEE Transactions on Power Delivery,12(4), pp. 1629- 1634.

[21] M. Ghandhari, G. Andersson, I.A. Hiskens, 2001, Control Lyapunov Functions for Series Devices," IEEE Transactions on Power Delivery, 16(4), pp. 689694 